\title{
Factors Affecting Implementation of Evidence Based Practice as Perceived by Nurses'
}

\author{
*Najla Akmal Sindi, Ghada Mahmed Hamouda, Maram Bankhar \\ Master student at King Abdul-Aziz Univercity \\ Associated Prof. of Nursing Administration, Alexandria University \\ Assistant Prof. of Nursing Administration, King Abdul-Aziz University \\ *Corresponding Author: Najla Akmal Sindi
}

\begin{abstract}
:
Background: Evidence based practice (EBP) involves taking the latest evidence from research studies and using the evidence as a guidance for patient care to achieve the best possible outcomes.

Aim: The study purposes to examine factors affecting implementation of EBP as perceived by nurses. Objectives: To identify the factors affecting the implementation of EBP in the clinical setting.

Methods: Quantitative, descriptive cross sectional research design was conducted in this study to describe contextual factors affecting EBP. Data was collected by using online questionnaire tool and printed paper questionnaire among nurses $(N=246)$.

Result: Organizational factors include providing continuous education on EBP not only one time. On the other hand, they provide opportunity for staff to ameliorate their skill for using in EBP implementation and organizational support. Individual factors involve creating inquiry culture and increasing nurses' awareness of strategies to implement EBP in the clinical practice. Additionally, time was the main barrier affecting EBP implementation.

Conclusion and Recommendations: This study suggests that nurses need more continuous EBP educational programs as part of system to enhance their knowledge and skill to implement EBP. Also, provide nurse facilitator who can supply nurses with the evidence and guide them to implement these evidences.
\end{abstract}

Keywords: Evidence Based Practice

Date of Submission: 16-06-2017

Date of acceptance: 22-07-2017

\section{Background}

Evidence based practice (EBP) involves taking the latest evidence from research studies and using the evidence as a guidance for patient care to achieve the best possible outcomes (Saba and McCormick, 2011and ANCC, 2013). The American Nurses Credentialing Center (ANCC), the Institute of Medicine (IOM), and the Joint Commission on Accreditation of Healthcare Organizations (JCIA) in the United State of America identifies evidence-based practice as a critical stage to improve healthcare quality. In the 21 st century, the IOM recognize EBP as a necessary competency for healthcare providers to improve patient outcome (Greiner and Knebel, 2003). The Institute of Medicine (IOM) aim and vision are that by 2020 the $90 \%$ of the clinical cases decisions will be based on evidence (IOM, 2010).

Nurses are in unique position to move the evidence to the practice. This position focusing on providing wellbeing of individual, families and communities. Thus, it is important to explore EBP impact on nursing (Schmidt and Brown, 2012). Furthermore, the use of evidence helps nurses to increase their confidence, adaptability, critical thinking, and decision-making skills required to deal with different diseases and patients in the health care (Melnyk and Fineout-Overholt, 2011). In addition, evidence utilization improves clinical performances of nurses, leads to better group cohesion, and higher job satisfaction (Saba and McCormick, 2011). Moreover, EBP is used as quality indicators for nurses' practice (Khammarnia et al., 2015).

Therefore, within clinical settings, it is important to note that EBP does not involve carrying out research, but rather using the findings of that research to deliver the best healthcare. Recently, there has been a huge shift towards the EBP because of the wide range benefits it has for the patient and hospitals (Cullen and Adams, 2010). When nurses incorporate the latest evidence into practice, patients receive high quality care, which results in improved patients' outcomes and satisfaction (Prior, Wilkinson, and Neville, 2010; Wallis, 2012). Furthermore, regarding organization benefit for EBP implementation it will reduce the cost (Warren et al., 2016). 
In healthcare settings implementing EBP considers as complicated task (Royle and Blythe 1998). Healthcare organizations must provide resources for EBP implementation and help in improving the of EBP society (DiCenso and Cullum 1998, Gerrish and Clayton, 2004). The resources such as education programs for EBP implementation, time, providing access to both staff and mentors to search for evidence, rewarding system and financial support to present EBP projects at conferences (Fitzsimons and Cooper, 2012).

Internationally, researchers have been undertaken which has identified both barriers and facilitators to the adoption of EBP. Previous studies have reported that lack of time, lack of skill to find research and lack of autonomy to change practice are major barriers to adopting EBP (Yadav and Fealy, 2011, Dalheim et al., 2012 and Sheifaz et al., 2014). Other completed studies recognize that support, recognition, and encouragement by administration and management are facilitators for evidence-based practice implementation (Sheifaz et al., 2014).

\section{Significance of the problem}

It seems from the above issue that it is important to identifying the factors that facilitate and promote EBP implementation. Furthermore, identifying the barriers affecting EBP implementation in the context of Saudi Arabia. Also, this study suggested at the end how to overcome the barriers affecting EBP implementation. The final finding of this study will support other healthcare organizations to develop EBP.

\section{Aim of the study}

The study purpose is to examine factors affecting EBP as perceived by nurses.

\section{Methods}

Quantitative, descriptive cross sectional research design was used in this study to describe factors affecting EBP as perceived by nurses. Official permission obtained from the administration of the Nursing College of King Abdul-Aziz University and governmental hospital in Jeddah Institutional Review Board (IRB) to collect data.

Online and printed paper questionnaire was used to obtain the data from the study subjects. Permission was obtained from Dr. Gulzar Malik 2014 to use her adapted questionnaire. Sample size was 290 nurses. The study was conducted at governmental hospital at Jeddah.

\section{Result and Discussion}

Table 1: Total mean and Standard Deviation Scores for Factors which promote EBP in the clinical setting

\begin{tabular}{|c|c|c|c|}
\hline Factors which promote EBP in the clinical setting & Mean & Std. D & Weighted mean \\
\hline 47.Nursing colleagues are supportive of my changing practice. & 3.46 & 1.03 & Agree \\
\hline 48. I find that Management are supportive in the use of evidence-based practice. & 3.50 & 1.13 & Agree \\
\hline 49. Doctors with whom I work are supportive of my changing practice. & 3.24 & .97 & Unsure \\
\hline 50. My organization supports my initiatives for change in practice. & 3.35 & 1.06 & Unsure \\
\hline 51. Organization provides me an opportunity to up skill myself in utilizing EBP. & 3.41 & 1.09 & Agree \\
\hline 52. My organization support research related activities. & 3.50 & 1.13 & Agree \\
\hline 53. I need an educational opportunity to enhance my inquiry, research and appraisal skills. & 3.50 & 1.13 & Agree \\
\hline $\begin{array}{l}\text { 54. I feel my organization should offer a continuing education courses on evidence-based } \\
\text { practice and its implementation }\end{array}$ & 3.53 & 1.21 & Agree \\
\hline
\end{tabular}

Table 2: Total mean and Standard Deviation Scores for Barriers to changing practice on the basis of best evidence

\begin{tabular}{|c|c|c|c|}
\hline Barriers to changing practice on the basis of best evidence & Mean & Std. D & $\begin{array}{l}\text { Weighted } \\
\text { mean }\end{array}$ \\
\hline 55. There is insufficient time at work to implement EBP. & 3.20 & 1.09 & Unsure \\
\hline 56. There are no incentives to develop my research skills to use in clinical practice. & 3.04 & .95 & Unsure \\
\hline 58. The culture of my ward / organization is not receptive towards changing practice. & 2.68 & 1.00 & Unsure \\
\hline 59. I lack the authority in the work place to change practice. & 2.83 & 1.04 & Unsure \\
\hline 60. There are insufficient resources (equipment) to change practice. & 2.91 & .99 & Unsure \\
\hline $\begin{array}{l}\text { 62. I find it difficult to identify the implications of organizational information to } \\
\text { change practice. }\end{array}$ & 2.85 & .91 & Unsure \\
\hline $\begin{array}{l}\text { 63. I think it would be difficult to overcome the barriers to achieve evidence-based } \\
\text { practice. }\end{array}$ & 2.84 & .89 & Unsure \\
\hline
\end{tabular}


Factors Affecting Implementation of Evidence Based Practice as Perceived by Nurses'

Table 3: Total mean and Standard Deviation Scores for How I promote Evidence- Based Practice

\begin{tabular}{|l|l|l|l|}
\hline How I promote Evidence- Based Practice & M & Std. D & $\begin{array}{l}\text { Weighted } \\
\text { mean }\end{array}$ \\
\hline 64. I am confident in establishing evidence-based nursing culture in my area of practice. & 3.37 & .93 & Unsure \\
\hline 65. I encourage questioning of clinical practice during individual / group discussion. & $\mathbf{3 . 4 5}$ & .96 & Agree \\
\hline $\begin{array}{l}\text { 66. I am aware of the strategies I can use to promote evidence-based practice in the clinical } \\
\text { setting. }\end{array}$ & $\mathbf{3 . 4 0}$ & .92 & Agree \\
\hline 67. I direct staff towards resources of evidence-based practice. & 3.37 & .89 & Unsure \\
\hline $\begin{array}{l}\text { 68. I have an ability to empower other nurses to bring change in practice/ utilize evidence-based } \\
\text { practice. }\end{array}$ & 3.30 & .87 & Unsure \\
\hline 69. I am able to initiate evidence-based activities and programs in my ward / department. & 3.32 & .89 & Unsure \\
\hline 70. I teach nurses/ students the methods of accessing and searching for best practice evidence. & $\mathbf{3 . 2 7}$ & .95 & Unsure \\
\hline 71. I incorporate evidence-based practice guidelines in my teaching. & 3.30 & .97 & Unsure \\
\hline
\end{tabular}

In relation to factors that promote EBP in the clinical setting (Table 1). The result of this study found that nurses felt that this organization should offer a continuing educational courses on EBP and its implementation. As well as, nurses need more educational opportunities to enhance their inquiry, research and appraisal skill. The possible explanation for this result maybe that this hospital is applied EBP by unit and this course is obligated as part of system and all staff on this hospital have opportunity to be trained on EBP. It's required only one time. Therefore, there is need to be given more than one time as a part of system. This finding is matching with the finding of Wallen et al., (2010) who found that to achieve successful implementation of EBP organization must provide intensive educational courses for nurses' and similar with finding of Warren et al., (2016) who found that extensive educational interventions is needed to achieve the implementation of EBP. Furthermore, this finding is matching with the finding of Malik et al., 2016 who found that nurses agreed that organization should offer education opportunity for nurses to enhance their research and critical appraisal skills in EBP implementation.

However, this study found that management is supportive in the use of EBP and support research related activities. The reason for this result may due to that this hospital has research center which support staff nurses and encourage them to involve in the EBP projects and hospital providing several resources such as expert staff nurse in researches, skill lab and data bases to implement EBP. Leaders are involved in implementing EBP also, acting as role model to influence nurses behaviour to implement EBP. In addition, hospital provides adequate time for nurses to implement EBP. According to Wallen et al., 2010 there are numerous strategies to achieve success to implement EBP: include leaders are supporting an EBP culture, availability of resources, support from experts on EBP process and educational opportunity to develop EBP skills. This result is matching Majid et al., 2012 findings who stated that nurses need adequate training in EB, time to learn and implement EBP, availability of mentors' nurses who had adequate experience with implementing EBP and management support. Although, this finding matching with finding of Warren et al., (2016) who found that Human, material, technological resources are important to shift the culture of the hospital to be based on EBP.

However, the findings of the current study demonstrated that nurses perceived that their organization provide the opportunity to up-skill their selves in utilizing EBP. The reason for this result may related to that the staff nurses are engage with different EBP projects. This finding does not support the previous research of Malik, 2014 which found that nurses disagreed that the organization provided them opportunities to up-skill in utilizing EBP.

Although, this hospital applied EBP. The nurses perceived several barriers (Table 2). Nurses reported that time are the main and a major barrier to implementing EBP. It is difficult to explain this result, but it might be that the nurses were required in this hospital to work twelve hours' shift. In addition, the nurses experience unit workload because in each unit has different goals and for each goal have several tasks and these tasks assigned by nurses beside patient care as requirement of magnet hospital. This finding is in agreement with Mohsen et al., (2016), Brown et al., (2009), Yoder et al., (2014) and Shifaza et al., (2014) findings which showed the time is a main factor affecting EBP implementation.

The other barrier was about there are no incentives to develop nurses research skills in clinical practice. It may be that this hospital is providing vouchers and appreciative certification as incentives for their staff. However, it seen that there is a need for more incentive to be provided by the organization to develop nurses research skills to use in clinical practice. In accordance with the present results, previous study done by DeBruyn et al., (2017) have demonstrated that lack of institutional incentives for developing research skills, conducting nursing research or implementing evidence-based practices.

Regarding factors for how Individual Promote Evidence-Based Practice (Table 3). The results of this study showed that nurses are encouraging questioning of clinical practice during individual /group discussion. Questioning of clinical practice is encouraged in this hospital by having unit-based councils. Units based councils in this hospital is responsible to raise practice and unit issues to the hospital management or 
administration. Then by a collaboration of between these councils and administration can improve any practice issue raised by the unit councils and thus members in each unit council will be empowered to ask any clinical question. The findings of the current study are consistent with these of Malik et al., (2016) who found that majority of nurses used questioning skills during individual/group discussion. And of (Melnyk and FineoutOverholt, 2011) who conclude that Spiriting of inquiry culture can help individual or group comfortable to asking questions regarding any practice this can succeed to promote EBP in the organization. Also, Wilson et al., (2015) concluded that the environment that promotes a spirit of inquiry and continuous learning culture will encourage staff to ask clinical question. While Fray (2011) who found the Unit, Councils had multi function such as improving clinical practice by encouraging questioning.

Moreover, the current study result found that nurses were aware of the strategies that can use to promote evidence-based practice in the clinical setting. This result may be explained by the fact that this hospital provides the baseline of EBP which result to increase nurses' awareness to EBP and this can be seen when nurses attending Journal club and they are aware of the strategies of EBP as well as they will look for information alone and discuss the finding with other. This result consisted with finding of Laaksonen et al., (2013) who found that the advantage of Journal club to increase nurses' awareness toward EBP implementation and knowledge. also, recommended as learning methods for nurses. These results differ from the published study done by Weng et al., (2013) who demonstrate that the Physicians and pharmacists were more aware of EBP than were the other professional groups such as nurses when attending EBP workshop.

\section{Conclusion}

Considering the factors affecting EBP either promoting or hindering EBP implementation. Furthermore, factors promoting EBP there were organizational factors include providing continuous education on EBP not only one time, provide opportunity for staff to up their skill for using in EBP implementation and organizational support. However, individuals' factors such as create inquiry culture and increase nurses' awareness of strategies to implement EBP in the clinical practice. Additionally, time was the main barriers affecting EBP implementation.

\section{Recommendation for education}

\section{Recommendation}

The evidence from this study suggests that nurses need more continuous EBP educational programs as part of system to enhance their knowledge and skill to implement EBP by planning to have comprehensive educational program about EBP implementation. Also, provide nurse facilitator that can supply nurses with the evidence and guide them to implement this evidence.

\section{Recommendation for administration}

The results of this study indicate that time is a major barrier for implementing EBP. So, hospital management can arrange for nurses more time off from their work to learn more about EBP and implement these knowledge to their practice. Also, may staff need more incentives other than voucher and appreciate certification.

\section{References}

[1]. American Nurses Credentialing Center. (2013). The Magnet Model Components and Sources of Evidence. Silver Spring, MD: American Nurses Credentialing Center

[2]. Cullen, L., \& Adams, S. (2010). What is evidence-based practice? Journal of Perianethesia Nursing, 25(3), 171-173. doi:10.1016/j.jopan.2010.03.004

[3]. Dalheim, A., Harthug, S., Nilsen, R. M., \&Nortvedt, M. W. (2012). Factors influencing the development of evidence-based practice among nurses: a self-report survey. BMC Health Services Research, 12(1), 1-10.

[4]. DeBruyn, R. R., Ochoa-Marín, S.C. and Sonia Semenic, S. (2017) Barriers and Facilitators to Evidence-Based Nursing in Colombia: Perspectives of Nurse Educators, Nurse Researchers and Graduate StudentsInvestigación y EducaciónenEnfermería, nursing research and education $\mathrm{Vol} 35$, No 1

[5]. DiCenso A. \& Cullum N. (1998) Implementing evidence-based nursing: some misconceptions. Evidence-Based Nursing 1, 38-40

[6]. Fitzsimons, E. \& Cooper, J. (2012)Embedding a culture of evidence-based practice. Nursing Management 2012 19: 7 , 14 -19

[7]. Fray, B. (2011). Evaluating Shared Governance: Measuring Functionality of Unit Practice Councils at the Point of Care. Creative Nursing, 17(2), 87-95. doi:10.1891/1078-4535.17.2.87

[8]. Gerrish K. \& Clayton J. (2004) Promoting evidence-based practice: an organizational approach. Journal of Nursing Management $12,114-123$.

[9]. Greiner A.C. \&Knebel, E. (2003) Health professions education: a bridge to quality. National Academies Press, Washington

[10]. Institute of Medicine. (2010). The future of nursing: Leading change, advancing health. Washington, DC: The National Academies Press.

[11]. Khammarnia, M., Mohammadi, M. H., Amani, Z., Rezaeian, S., \&Setoodehzadeh, F. (2015). Barriers to Implementation of Evidence Based Practice in Zahedan Teaching Hospitals, Iran, 2014. Nursing Research and Practice,2015, 1-5. doi: $10.1155 / 2015 / 357140$

[12]. Laaksonen, C. ,Paltta, H. , Schantz, M. ,Ylönen,M. , Soini, T.(2013) Journal club as a method for nurses and nursing students' collaborative learning: a descriptive study Health Science Journa Volume 7 Issue 3 
[13]. Majid, S., Foo, S., Luyt, B., Zhang, X., Theng, Y. L., Chang, Y. K., \& Mokhtar, I. A. (2011). Adopting evidence-based practice in clinical decision making: nurses' perceptions, knowledge, and barriers. Journal of the Medical Library Association: JMLA, 99(3), 229.

[14]. Malik, G., McKenna, L., \& Plummer, V. (2014). Perceived knowledge, skills, attitude and contextual factors affecting evidence-based practice among nurse educators, clinical coaches and nurse specialists. International journal of nursing practice, 21(S2), 46-57.

[15]. Malik, G., McKenna, L., \& Plummer, V., (2016) Facilitators and barriers to evidence-basedpractice: perceptions of nurse educators, clinical coaches and nurse specialists from a descriptive study. Journal Volume 52, 2016 - Issue 5: Special Issue: Contemporary Issues in Nursing Education

[16]. Melnyk B. M., Fineout-Overholt E, (2011)Evidence-based Practice in Nursing \& Healthcare: A Guide to Best Practice $2^{\text {nd }}$ ed

[17]. Mohsen M, Safaan N, and. Okby O,.(2016) "Nurses' Perceptions and Barriers for Adoption of Evidence Based Practice in Primary Care: Bridging the Gap." American Journal of Nursing Research, vol. 4, no. 2 : 25-33. doi: 10.12691/ajnr-4-2-1.

[18]. Prior, P., Wilkinson, J. \& Neville, S. (2010). Practice nurse use of evidence in clinical practice: A descriptive study. Nursing Praxis in New Zealand, 26(2), 14-25.

[19]. Prior, P., Wilkinson, J. \& Neville, S. (2010). Practice nurse use of evidence in clinical practice: A descriptive study. Nursing Praxis in New Zealand, 26(2), 14-25.

[20]. Royle J. \& Blythe J. (1998) Promoting research utilisation in nursing: the role of the individual, organisation, and environment. Evidence-Based Nursing 1, 71-72.

[21]. Saba, V. K. \& McCormick, K. A. (2011). Essentials of Nursing Informatics. New York, NY: McGraw-Hill Companies

[22]. Schmidt, N. A., \& Brown, J. M. (2012). Evidence-based practice for nurses: appraisal and application of research. Sudbury, MA: Jones \& Bartlett Learning.

[23]. Shifaza, F., Evans, D., \& Bradley, H. (2014). Nurses' Perceptions of Barriers and Facilitators to Implement EBP in the Maldives. Advances in Nursing, 2014.

[24]. Wallen G.R., Mitchell S.A., Melnyk B., Fineout-Overholt, E., Miller-Davis, C., Yates, J., \& Hastings, C. (2010). Implementing evidence-based practice: effectiveness of a structured multifaceted mentorship programme. Journal of Advance Nursing. 66(12):2761-2771. doi:10.1111/j.1365-2648.2010.05442.x

[25]. Wallis, L. (2012). Barriers to implementing evidence-based practice remain high for US nurses. AJN, The American Journal of Nursing, 112(12), 15.

[26]. Warren, J. I., Mclaughlin, M., Bardsley, J., Eich, J., Esche, C. A., Kropkowski, L., \&Risch, S. (2016). The Strengths and Challenges of Implementing EBP in Healthcare Systems. Worldviews on Evidence-Based Nursing, 13(1), 15-24. doi:10.1111/wvn.12149

[27]. Weng, Y., Kuo, K. N., Yang, C., Lo, H., Chen, C., \& Chiu, Y. (2013). Implementation of evidence-based practice across medical, nursing, pharmacological and allied healthcare professionals: a questionnaire survey in nationwide hospital settings. Implementation Science, $8(1)$. doi:10.1186/1748-5908-8-112

[28]. Wilson, M., Sleute, M., Newcomb, P., Behan, D., Walsh, J., Wells, J. N., \& Baldwin, K. B. (2015). Empowering Nurses With Evidence-Based Practice Environments: Surveying MagnetR, Pathway to ExcellenceR, and Non-Magnet Facilities in One Healthcare System. Sigma Theta Tau International, 12-21. doi:10.1111/wvn.12077

[29]. Yadav, B. L., \&Fealy, G. M. (2011). Irish psychiatric nurses' self-reported sources of knowledge for practice. Journal of Psychiatric and Mental Health Nursing,19(1), 40-46. doi:10.1111/j.1365-2850.2011.01751.x

Najla Akmal Sindi. "Factors Affecting Implementation of Evidence Based Practice as Perceived by Nurses'." IOSR Journal of Mechanical and Civil Engineering (IOSR-JMCE) 6.4 (2017): 53-57. 